\title{
RESIDUAL STRESSES IN ORTHOGONAL CUTTING OF METALS: THE EFFECT OF THERMOMECHANICAL COUPLING PARAMETERS AND OF FRICTION
}

\author{
M. H. Miguélez ${ }^{1}$, R. Zaera ${ }^{2}$, A. Molinari ${ }^{3}$, R. Cheriguene ${ }^{1}$, \\ and A. Rusinek ${ }^{4}$ \\ ${ }^{1}$ Department of Mechanical Engineering, Universidad Carlos III, \\ Leganés, Madrid, Spain \\ ${ }^{2}$ Department of Continuum Mechanics and Structural Analysis, \\ Universidad Carlos III de Madrid, Leganés, Madrid, Spain \\ ${ }^{3}$ Laboratory of Physics and Mechanics of Materials, Université Paul \\ Verlaine-Metz, Metz cedex, France \\ ${ }^{4}$ National Engineering School of Metz (ENIM), Laboratory of Mechanical \\ Reliability (LFM), Ile du Saulcy, Metz, France
}

\begin{abstract}
The generation of residual stresses in orthogonal machining is analysed by using an Arbitrary Lagrangian Eulerian (ALE) finite element approach. It is shown that a substantial level of tensile residual stresses can be obtained in the vicinity of the machined surface without any contribution of thermal effects. This motivates the development of a parametric study to analyse the effects of the thermomechanical coupling parameters on residual stresses. The roles of thermal expansion, of thermal softening and of the Taylor-Quinney coefficient (controlling the heat generated by plastic flow) are considered separately. The influence of friction is also analysed by assuming dry cutting conditions and a Coulomb friction law. The friction coefficient has a complex effect by controlling heat generation (frictional heating) along the tool rake and clearance faces and the propensity for the chip to stick to the tool. Geometrical effects such as the tool rake angle and the tool edge radius are also discussed.
\end{abstract}

Keywords: Friction; Orthogonal machining; Parametric analysis; Residual stresses; Thermomechanical coupling parameters

\section{INTRODUCTION}

The reliability of structural components obtained by machining operations is influenced by the state of residual stresses resulting from processing. Having tensile residual stresses in the vicinity of the machined surface has negative effects on fatigue and fracture resistance, on stress corrosion [1] and can substantially

The authors are indebted, for the financial support of this work, to the Ministry of Science and Education of Spain (under project DPI2005-08018) and to the Comunidad Autónoma de Madrid and University Carlos III of Madrid (under project CCG07-UC3M/DPI-3396).

Address correspondence to M. H. Miguélez, Department of Mechanical Engineering, Universidad Carlos III, Avda Universidad 30, Leganés 28911, Madrid, Spain. E-mail: mhmiguel@ing.uc3m.es 
reduce the component life. Therefore, the analysis of the residual stresses due to machining operations has been an active subject of research. However, machining is a complex process where large strains and strain-rates are produced and where large temperatures are generated by dissipation of the plastic work and by frictional heating. The complexity of the physics of chip formation and the variety of boundary conditions (the chip has a free surface while also sustaining sticking and frictional sliding along the tool rake face; the workpiece is in contact with the tool at the clearance surface) lead to difficulties in analysing the generation of residual stresses by pure analytical methods, although some authors have used this approach to predict residual stresses after machining [2].

Thus, Finite Element analysis has played an important role in simulating and analysing the machining process (see reviews and bibliography in references [3-5]). Many aspects related to residual stresses in machining have been covered by these analyses. It has been noted that tensile residual stresses can result from the competition between mechanical and thermal effects [6]. The tensile or compressive nature of residual stresses depends not only on machining parameters such as cutting speed, feed rate, rake angle, but also on the tool geometry and the lubrication conditions [7]. The effects of the tool-edge radius on residual stresses were analysed by several authors, see, for example, Nasr et al. [8], and it was shown by [9] that the level of tensile residual stresses increases with rake angle, cutting edge radius and feed. The increase of friction was found to influence the resultant tensile residual stress [10], however no explanation about the mechanisms involved in this behaviour has been found.

Different Finite Element analyses have been carried out to describe residual stresses due to orthogonal cutting of AISI 316L or AISI 1045 steels, Nasr et al. [8], Salio et al. [11] Outeiro et al. [12, 13] and compared to experimental data of M'Saoubi et al. [14]. Finally, the influence of tool coating was analysed in [15] and the effect of sequential cuts in [16].

It is commonly admitted that tensile residual stresses in machining result from the heating of the machined surface during the cutting operation. The large temperature level reached in a thin thermally affected layer near the workpiece surface produces thermal expansion and plastic flow. During the subsequent cooling the thermal contraction of this layer is higher than in the workpiece in-depth, and this phenomenon is believed to be at the origin of tensile residual stresses observed in machining. The common understanding is that, in the absence of thermal effects, the mechanical loading exerted onto the workpiece leads to compressive residual stresses. On the other hand, it is possible to find the opposite assertion in Lin et al. [17], where a study on residual stresses is developed with numerical and analytical techniques. These authors showed tensile residual stresses after mechanical loading, with a negligible influence of thermal effects.

In the present paper it is shown that even in the absence of thermal effects, a substantial level of tensile residual stresses can be obtained by pure mechanical effects solely. However the level of tensile residual stress is also strongly influenced by thermal effects. This result suggests reconsidering the analysis of residual stresses by developing a systematic analysis where the output of each parameter is studied separately. This is possible within the finite element framework, by successively switching off and on the physical parameter under consideration to quantify its effect. In this work an A.L.E. model of orthogonal cutting is developed with 
the commercial finite element code ABAQUS/Explicit. The numerical model is described later in perspective with respect to previous finite element analyses of machining.

Our primary focus is to understand and quantify how residual stresses are controlled by thermomechanical coupling parameters. In our analysis, we consider the influence of thermomechanical coupling parameters such as thermal expansion, thermal softening, the Taylor-Quinney coefficient (characterizing the proportion of the plastic work transformed into heat) and the friction coefficient (controlling frictional heating). Geometrical effects such as the tool rake angle and the tool edge radius are also discussed. Dry cutting conditions are assumed and a Coulomb friction is considered. The friction coefficient has a complex effect by controlling heat generation along the tool rake and clearance faces and the propensity for the chip to stick to the tool. How residual stresses are affected by the interplay of these phenomena is an interesting question analysed in this paper.

\section{NUMERICAL MODEL AND EXPERIMENTAL VALIDATION}

Eulerian, Lagrangian and Arbitrary Lagrangian-Eulerian (A.L.E.) techniques have been used to simulate orthogonal cutting [18, 19]. In Lagrangian analysis, the computational grid deforms with the material whereas in Eulerian analysis it is fixed in space. The Lagrangian calculation embeds a computational mesh in the material domain and solves for the position of the mesh at discrete points in time. The Eulerian formulation has been used to model orthogonal metal cutting as a steady process of chip formation [20, 21]. The advantage of using Eulerian formulation is that fewer elements are required to model the workpiece and the chip, thus reducing computational time. The drawback of this approach is a need in determining chip geometry and shear angle experimentally prior to the simulation. A vast majority of models are based on the Lagrangian formulation, which allows the chip to be modelled from incipient to steady state. Using the Lagrangian formulation with no adequate remeshing requires a failure criterion to describe the separation of the chip from the workpiece. As a result, the development of a realistic separation criterion has been an important factor in earlier FE modeling of cutting with Lagrangian formulation approaches. In contrast, an updated Lagrangian formulation with adaptive mesh or automatic remeshing does not require a chip separation criterion. This has been successfully applied in simulation of continuous and segmented chip formation in machining processes [22-26].

In recent studies, Bäker et al. [27] simulated adiabatic shearing and serrated chip formation when cutting with a sharp edge cutting tool, using Lagrangian analysis with frequent remeshing and employing a damage criterion. A.L.E. is a relatively new modelling technique in machining, including a combination of the Lagrangian and Eulerian approaches without having their drawbacks. It was firstly introduced to model the cutting process by the end of the last decade. Some of recent A.L.E. cutting models were presented in [28-30]. This approach became popular due to its implementation in commercial finite element codes [31]. Explicit dynamic A.L.E. formulation is very efficient for simulating highly non-linear problems involving large localized strains. Detailed formulation for an A.L.E. approach can be found in different references, see for instance [32]. A brief 
summary of the theoretical fundamentals for A.L.E. approach in simulation of cutting presented by Pantale et al. in [33] is included below.

As is well known, the A.L.E. approach is an extension of both Lagrangian and Eulerian descriptions, since the mesh does not remain fixed in space neither moves attached to material points. Then, the grid points have their own motion governing equations. In A.L.E. description, material points are represented by a set of Lagrangian coordinates $\vec{X}$, spatial points with a set of Eulerian coordinates $\vec{x}$, and reference or grid points with a set of arbitrary coordinates $\vec{\xi}$. At time $t$ a spatial point $\vec{x}$ is obtained by mapping a material point $\vec{X}$ with the material motion $\vec{x}=\Psi(\vec{X}, t)$ or by mapping a reference point $\vec{\xi}$ with the grid motion $\vec{x}=\Psi(\vec{\zeta}, t)$. The material velocity $\vec{v}$ of the particles is obtained using a classical material derivative:

$$
\vec{v}=\dot{\vec{x}}=\left.\frac{\partial \vec{x}}{\partial t}\right|_{\vec{X}=c t e}
$$

The grid velocity $\overrightarrow{\hat{v}}$ is obtained after the introduction of a mixed derivative, which represents the time variation of a physical quantity for a given grid point:

$$
\overrightarrow{\hat{v}}=\stackrel{\circ}{\vec{x}}=\left.\frac{\partial \vec{x}}{\partial t}\right|_{\vec{\zeta}=c t e}
$$

Mass, momentum and energy conservation laws in A.L.E. description are used in a similar form as in Eulerian description. Taking into account the definition of the convective velocity $\vec{c}=\vec{v}-\overline{\hat{v}}$, conservation laws for A.L.E. approach are written as:

$$
\begin{gathered}
\stackrel{\circ}{\rho}+\vec{c} \nabla \rho+\rho \operatorname{div} \vec{v}=0 \\
\rho \stackrel{\circ}{\vec{v}}+\rho \vec{c} \nabla \vec{v}=\vec{f}+\operatorname{div} \sigma \\
\rho \stackrel{\circ}{e}+\rho \vec{c} \nabla e=\sigma: \mathbf{D}-\operatorname{div} \vec{q}+r
\end{gathered}
$$

where $\nabla$ is the gradient operator, $\rho$ is the mass density, $\vec{f}$ are the body forces, $\sigma$ is the Cauchy stress tensor, $e$ is the specific internal energy, $\mathbf{D}$ is the strain rate tensor, $r$ is the body heat generation (ohmic resistance, inductive heating...) and $\vec{q}$ is the heat flux vector. According to the characteristics of the machining problem, temperature is considered as unique component of internal energy, body heat generation is neglected, mechanical dissipation is associated to plastic deformation, and Fourier's heat conduction law rules the heat flow. Then, the First Law of Thermodynamics (Eq. (5)) may be simplified:

$$
\rho c_{V} \stackrel{\circ}{\theta}+\rho c_{V} \vec{c} \nabla \theta=\beta \sigma: \mathbf{D}^{P}+k \Delta \theta
$$

$\theta$ being the temperature, $c_{V}$ being the specific heat, $k$ the thermal conductivity coefficient, $\mathbf{D}^{P}$ the plastic strain rate tensor, $\Delta$ the Laplacian operator, and $\beta$ the fraction of plastic work converted into heat (Taylor-Quinney coefficient) included to match experimental results. 


\section{Model Description}

A plane strain A.L.E. model was developed in the commercial Finite Element code ABAQUS/Explicit. The geometry of the baseline model (zero rake angle, cutting edge radius $0.02 \mathrm{~mm}$ ) was modified to analyse different tool rake angles (zero, positive and negative) and different cutting edge radii (from 0.02 to $0.15 \mathrm{~mm}$ ). It is critical to avoid mesh influence in the results, because of the parametric study. One of the requirements of the model is to avoid mesh distortion from conditions of frictionless to elevated friction.

A specific mesh is defined for a given tool geometry and is used to perform all calculations related to this geometry. This requirement is useful to avoid other influencing factors related with numerical modelling, such as mesh size.

A thermomechanical coupled analysis was developed, with CPE4RT element type (see ABAQUS/Explicit manual [34]). These are plane strain, quadrilateral, linearly interpolated, and thermally coupled elements with reduced integration and automatic hourglass control, for A.L.E. formulation.

Analysis was carried out in two steps. In the first step, cutting was modelled at constant cutting speed and steady state conditions were reached. In the second step, the workpiece was unloaded and cooled. The residual stress distribution was obtained in a section of the workpiece corresponding to stationary conditions during cutting.

The characteristics of the numerical model are shown in Figure 1. The tool is fixed and the cutting speed is applied to the workpiece. Cutting takes place in the plane 1-2 under plane strain conditions. Continuous chip formation is assumed. Many A.L.E. models developed in the literature impose Eulerian contours allowing the material to flow in a similar way as a fluid [35, 36]. The objective of the simulation being to obtain the residual stress distribution, the model should include the unloading and cooling stages. In this case, the A.L.E. model should utilize sliding and Lagrangian contours (see ABAQUS/Explicit manual [34]) making possible the flow of the material across an internal Eulerian zone surrounding the tool tip. This approach avoids extreme distortion of the mesh,

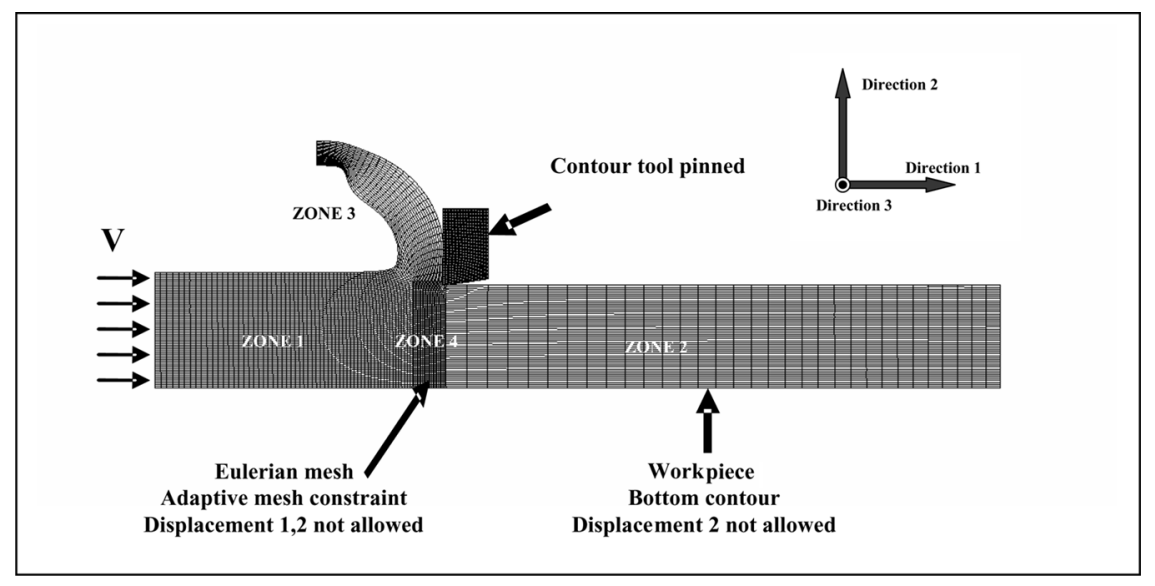

Figure 1 Model geometry and contour conditions. 
allowing the simulation of processes involving different friction coefficients with the same original mesh.

As was said previously, A.L.E. combines the advantage of Lagrangian and Eulerian formulations. The model was divided in several zones allowing mesh motion or material flow across the fixed mesh, depending on which zone is considered in the model. Zones 1, 2 and 3 combine Lagrangian boundaries with sliding boundaries (where the flow of the material can be tangential to the contour, but cannot go across this boundary). Zone 4 is an Eulerian region, with the mesh fixed, allowing the flow of the material across this region. The main advantage of this technique is that distortion is avoided in the region surrounding the tool tip, together with the absence of separation criterion, which is always an artificial parameter in Lagrangian models. Another advantage is that it is not necessary to establish the separation line, allowing for instance, the simulation of negative tool rake angles. However chip segmentation cannot be modelled with this technique. Therefore this model could become unrealistic when high-speed machining with chip segmentation is simulated, or thermo-resistant alloys are studied. Another drawback is the initial definition of the chip. While the shape of the uncut chip is defined previously to the analysis, the shape of the chip during cutting and the level of element distortion depend strongly on the parameters of the simulation (for example, friction coefficient). The main problem is to establish for a given tool geometry (after some simulations) an initial mesh that will be used later for various values of the material parameters.

Concerning the ratio of plastic work converted into heat, a value of the Quinney-Taylor coefficient equal to 0.9 is assumed, as it is widely accepted in literature [37, 38]. An initial temperature of $293 \mathrm{~K}$ has been imposed. Conduction and convection to air (only in freshly machined surface) were taken into account. The heat flux $q_{h}$ on the external surface, which governs the heat transfer due to convection, is given by:

$$
q_{h}=h\left(T_{w}-T_{0}\right)
$$

where $h$ is the convection heat-transfer coefficient of the workpiece material $\left(10 \mathrm{~W} / \mathrm{m}^{2} \mathrm{~K}\right)$ and $T_{w}$ is the sink temperature $(293 \mathrm{~K})$.

Friction is one of the hardest phenomena to simulate in machining. Several authors have accorded a particular attention to the improvement of friction formulation $[39,40]$. In the present work, a constant coefficient of friction along the tool/workpiece contact length is assumed. Although the classical Coulomb friction law is the simplest formulation, it has been widely used in numerical simulation of machining [41, 42]. The contacting bodies are assumed to stick together if $\|T\|<\mu\|N\|$ and in relative motion if $\|T\|=\mu\|N\|$ with $N$ and $T$ representing the normal and tangential components of the contact force at the interface, and $\mu$ the friction coefficient. This value was ranged from 0 to 0.4 with the aim to analyse the influence of friction on residual stresses. The value of the friction coefficient equal to 0.2 reproduces accurately the resultant residual stress observed in experimental tests.

The equation for the heat production by friction at the interface per unit surface $Q_{f}$ is given by:

$$
Q_{f}=\mu \sigma_{n} V_{s}
$$


where $\sigma_{n}$ is normal pressure and $V_{s}$ is sliding velocity. The heat partition between tool and workpiece was assumed to be 50-50\% [43]. The hypotheses related with the modelling of friction and heat partition have strong limitations. However the paper is not focused in the improvement of the knowledge related with these topics, so these hypotheses are considered to be accurate enough as a starting point in the analysis of residual stresses.

Many constitutive equations have been proposed to reproduce the thermomechanical effects involved in metal cutting [44]. In this work, the workpiece material is modelled using the Johnson-Cook (JC) constitutive model [45].

$$
\sigma_{Y}=\left(A+B\left(\varepsilon^{p l}\right)^{n}\right) \cdot\left(1+C \ln \left(\frac{\dot{\varepsilon}^{p l}}{\dot{\varepsilon}_{0}}\right)\right) \cdot\left(1-\left(\frac{\theta-\theta_{\text {ref }}}{\theta_{\text {melt }}-\theta_{\text {ref }}}\right)^{m}\right)
$$

$\sigma_{Y}$ being the flow stress, $\varepsilon^{p l}$ the equivalent plastic strain and all remaining parameters being material constants. This constitutive equation, available in ABAQUS/Explicit, is useful to simulate mechanical processes involving high strain and strain rates, and thermal softening, and it has been widely used to model cutting processes [46, 47].

Characterization of workpiece material AISI $316 \mathrm{~L}$ has received considerable attention in the literature. It is possible to found JC parameters in a wide range of values, associated to the thermomechanical behaviour of this alloy. Chandrasenkaran et al. [48] reported several sets of JC material constants for AISI $316 \mathrm{~L}$ used in the literature, showing large variety in the parameters; these differences may be explained by the previous thermomechanical histories suffered by the workpiece. The values of these constants influence the residual stresses obtained by numerical simulation. Nasr et al. [49] showed a considerable increase in residual stresses when initial yield stress $(A)$ decreases and when the strain hardening parameters $(B$ and $n$ ) increase. Some authors recommend, in the absence of any dedicated mechanical test method for describing the flow stress, the use of metal cutting results (cutting forces and chip morphology) to fit the constants of the Jonhson-Cook law [50]. In the present work the same approach was followed, starting from values proposed by other authors and proposing a new set that fits the values of cutting forces obtained experimentally (see Table 1). These parameters, chosen so as to get a good correlation with cutting force measurements, were validated by comparison against experimental measurements of residual stresses.

Orthogonal dry cutting tests with air cooling were carried out in a lathe (PINACHO model Smart-Turn 6/165) with the following parameters: cutting speed $120 \mathrm{~m} / \mathrm{min}$, feed rate $0.1 \mathrm{~mm} / \mathrm{rev}$, cutting width $2 \mathrm{~mm}$. Different tool geometries,

Table 1 Three sets of JC material constants for AISI 316L obtained from the literature (references $[48,50])$, and that proposed for the present work

\begin{tabular}{lcccccc}
\hline Reference & $A(\mathrm{MPa})$ & $B(\mathrm{MPa})$ & $n$ & $C$ & $m$ & $\dot{\varepsilon}_{0}\left(\mathrm{~s}^{-1}\right)$ \\
\hline Chandrasekaran et al. 1 [48] & 305 & 1161 & 0.610 & 0.010 & 0.517 & 1 \\
Chandrasekaran et al. 2 [48] & 305 & 441 & 0.100 & 0.057 & 1.041 & 1 \\
Tounsi et al. [50] & 514 & 514 & 0.508 & 0.042 & 0.533 & $10^{-3}$ \\
Present work & 400 & 750 & 0.500 & 0.040 & 0.500 & 1 \\
\hline
\end{tabular}


Table 2 Properties of the K313 (tool) and AISI 316L (workpiece) from reference [8]

\begin{tabular}{lcc}
\hline Property & K313 & AISI 316L \\
\hline Modulus of elasticity $(\mathrm{GPa})$ & 615 & 193 \\
Poisson's ratio & 0.22 & 0.3 \\
Density $\left(\mathrm{kg} / \mathrm{m}^{3}\right)$ & 14900 & 8000 \\
Specific heat capacity $(\mathrm{J} / \mathrm{kg} \mathrm{K})$ & 138 & 500 \\
Thermal conductivity $(\mathrm{W} / \mathrm{m} \mathrm{K})$ & 79 & 20 \\
Linear coefficient of thermal expansion $(\mathrm{mm} / \mathrm{mm} \mathrm{K})$ & - & $19.9 \mathrm{E}-6$ \\
\hline
\end{tabular}

generated by electro-discharge in a hard metal, were: cutting edge radius $20 \mu \mathrm{m}$, rake angles $-8^{\circ}, 0^{\circ}$ and $6^{\circ}$. These geometries were defined to match the characteristics of the tools considered in the numerical simulations. The physical properties of the tool material (Kennametal K313) and of the workpiece material (AISI 316L) have been found in recent work [8] and they are summarized in Table 2.

The workpiece material was a tube of AISI $316 \mathrm{~L}$ with a wall thickness $2 \mathrm{~mm}$. The support of the tool (Fig. 2(a)) was instrumented with strain gages allowing measurement of cutting force during orthogonal cutting of the tube. Cutting edge of the insert was located in the support coaxial with the axis of the support, avoiding the effect of torque during cutting. Several simulations were performed with the constitutive equations proposed in Table 1 to predict cutting force. The results of cutting force are depicted in Figure 2(b), showing good estimation of the cutting force with the constitutive equation selected.

\section{Model Validation}

The model was validated by comparing the residual stress field obtained numerically with experimental data reported in the literature. The model conditions

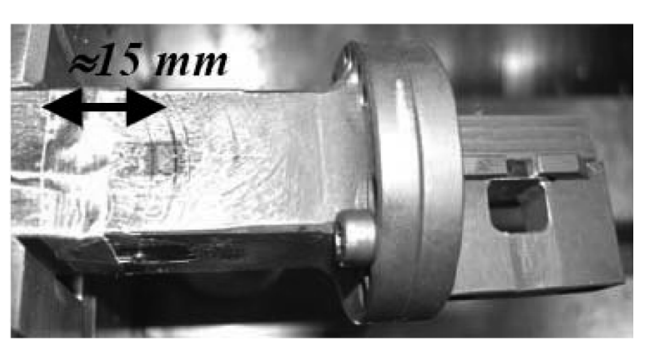

(a)

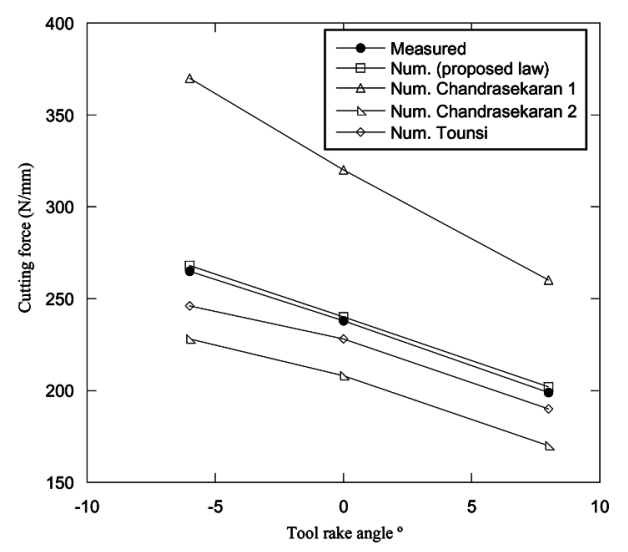

(b)

Figure 2 (a) Left, tool support for orthogonal cutting tests, instrumented for cutting forces measurement. (b) Right, cutting forces measured and simulated with constitutive laws available in literature and proposed in this paper. 


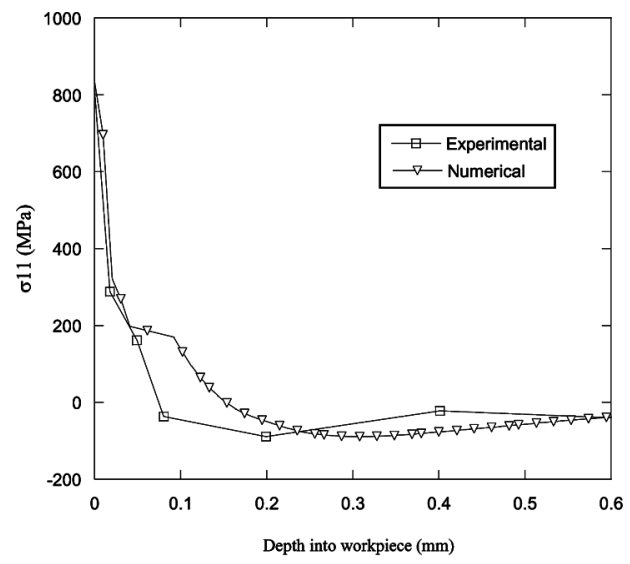

(a)

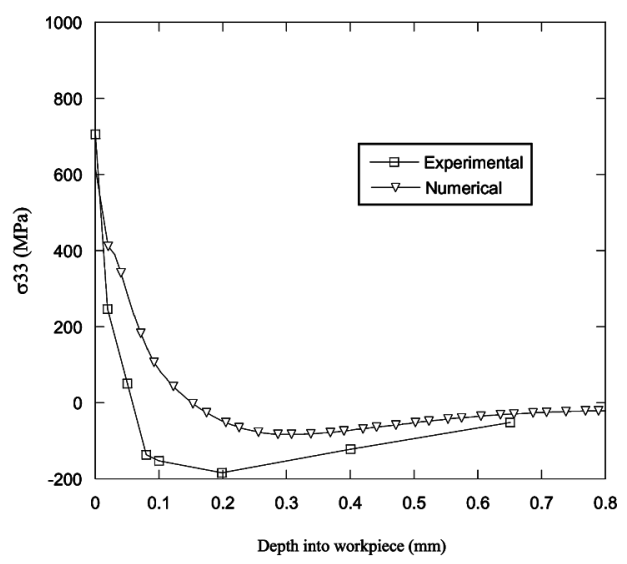

(b)

Figure 3 Experimental validation of the model. Distribution of residual stresses after turning test in AISI $316 \mathrm{~L}$ steel, cutting speed $100 \mathrm{~m} / \mathrm{min}$. (a) $\sigma_{11}$ is the circumferential stress, (b) $\sigma_{33}$ is the axial stress. Numerical results are those obtained in the present paper, experimental results are from M'Saoubi et al. [14].

for validation were: rake angle is 0 , cutting edge radius $R=0.02 \mathrm{~mm}$, cutting speed $V=100 \mathrm{~m} / \mathrm{min}$, friction coefficient $\mu=0.2$, feed rate $=0.1 \mathrm{~mm}$. Experimental results were obtained by M'Saoubi et al. [14]. The authors reproduced orthogonal cutting conditions obtained from turning tests. Figure 3 shows the correlation between numerical and experimental results.

From cutting force measurements performed in the present work and residual stresses measurements reported in the literature, it is concluded that the values of material parameters given in Table 1 are representative of the thermomechanical response of an AISI $316 \mathrm{~L}$ steel. This set of parameters will characterize the reference material in the parametric analyses carried out in the following of the paper.

\section{NUMERICAL RESULTS AND DISCUSSION}

\section{Effect of Mechanical Loading and of Thermal Expansion on Residual Stresses}

Residual stresses can be affected by mechanical loading and thermal effects. The heat increase due to plastic work and friction has a direct effect on the level of tensile residual stresses. First, thermal expansion is causing tensile stresses after cooling. However, secondly the increase of temperature produces thermal softening, which decreases the level of tensile stresses.

The influence of the thermal expansion of the workpiece material is firstly analysed. The cutting conditions are those given in the previous paragraph concerning the model validation, except for the cutting speed that is now fixed at $2 \mathrm{~m} / \mathrm{s}$ in all simulations performed in this work. The distribution of the residual stresses $\sigma_{11}$ and $\sigma_{33}$ (the directions $x_{1}, x_{2}, x_{3}$ are shown in Fig. 1), is calculated by taking the thermal expansion into account and is compared to the case where the thermal expansion coefficient is zero $(\alpha=0)$, see Figure 4. 


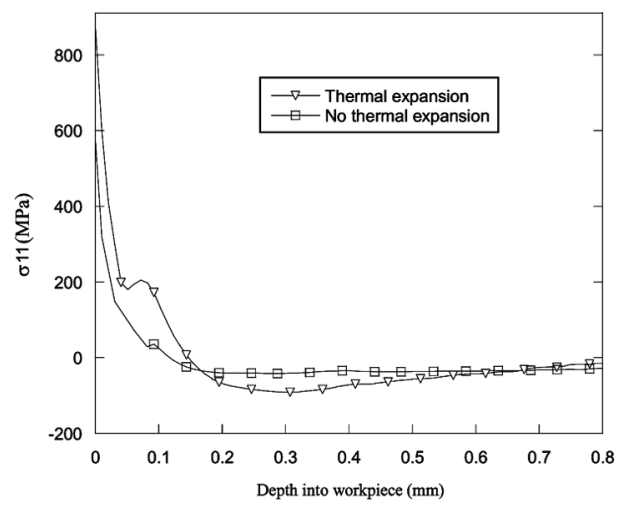

(a)

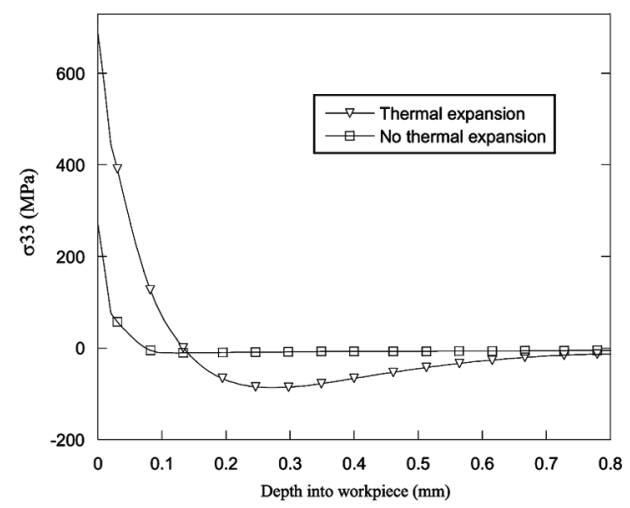

(b)

Figure 4 Distribution of residual stresses (a) $\sigma_{11}$, (b) $\sigma_{33}$ obtained with and without thermal expansion. Cutting speed $120 \mathrm{~m} / \mathrm{min}$, rake angle 0 , friction coefficient 0.2 .

It is well recognized that the thermal expansion coefficient $\alpha$ is a key parameter governing the level of tensile residual stresses in machining. Indeed the tensile stresses are observed in Figure 4 to be higher when thermal expansion is taken into account. When $\alpha=0$, an important observation is that tensile stresses are still present near the machined surface. It is worth to explain the generation of tensile stresses in the freshly machined surface in absence of thermal expansion and friction. This trend is observed with both the ALE and Lagrangian approach. Nevertheless it is quite difficult to observe the mechanical phenomena in the material during cutting in an ALE approach (because the mesh does not follow the material). Therefore a simple Lagrangian model was developed (see details of this kind of model in [36]). No friction and no thermal expansion were accounted in the model, and an erosion criterion was imposed in the workpiece to allow material separation. The same constitutive law was used to simulate the behaviour of AISI316L. Uncut thickness of the chip was $0.1 \mathrm{~mm}$, and the tool was completely sharp (cutting edge radius zero). The cutting velocity was $2 \mathrm{~m} / \mathrm{s}$.

The analysis of stress field $\sigma_{11}$ during cutting shows that machining acts like an extreme forming process and the mesh is deformed by the compression of the workpiece material ahead the tool tip. After cutting, the material behind the tool tip presents tensile stresses in direction 1 . The origin of these tensile residual stresses may be understood by performing an elemental one-dimensional analysis of the time history of the displacements in direction 1 at two nodes $A$ and $A^{\prime}$ that will be at the machined surface after cutting (depicted in Fig. 5(a)). As shown in Figure 5(b), both nodes undergo the same displacements with a delay in time that corresponds to the separation between them divided by the cutting velocity $V$. The maximum displacement for each point corresponds to the time at which the tool tip is straight over it. Then, the field of displacements may be described as a "displacement wave" travelling at a velocity $V$ in the cutting direction $u_{1}=$ $g(x+V t)$ (Fig. 8(b)). The corresponding strain may be then calculated as $\varepsilon_{1}=$ $\partial g(x+V t) / \partial x$ as can be seen in Figure 6(a). The material at the machined surface is compressed to a maximum value beyond the yield strain and then stretched again 


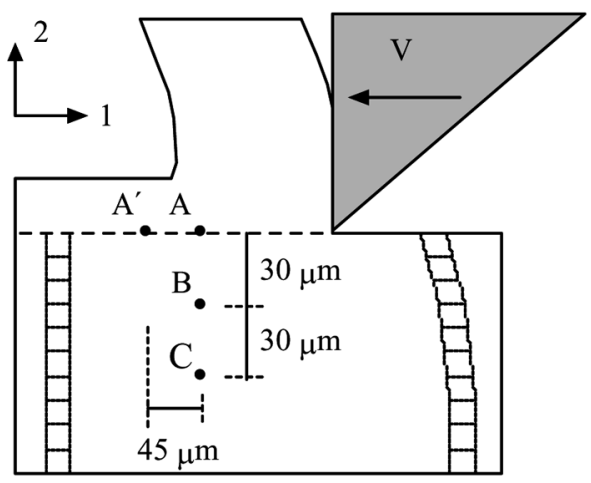

(a)

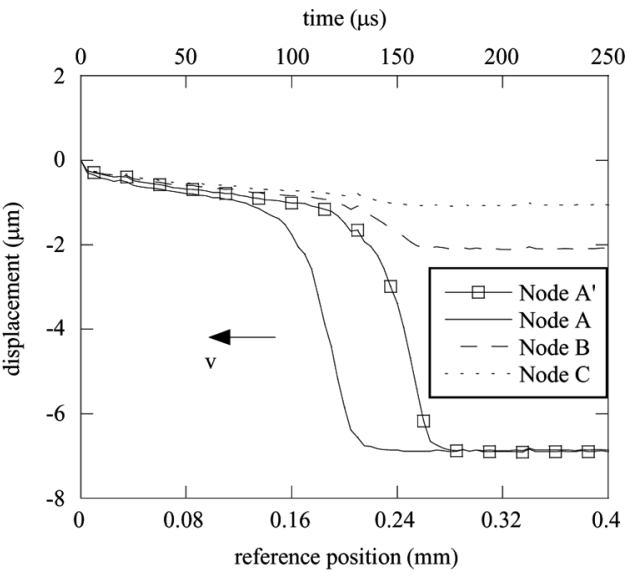

(b)

Figure 5 (a) Position of reference nodes $A, A^{\prime}, B$ and $C$. (b) Time-history of displacements in direction 1 of the reference nodes $A, A^{\prime}, B$ and $C$.

to its original length. This produces a stress path that ends with tensile values (Fig. 6(b)). Stretching in direction 1 also results in tensile stresses in direction 3 due to the plane strain condition. The value of the residual tensile stress is then directly related with the maximum compressive strain undergone by the material point. Plotting the time-history of displacements at nodes $B$ and $C$ below the machined surface (Fig. 5(b)), it can be seen that the maximum slope of the displacement wave decreases with depth, as well as the maximum strain (Fig. 6(a)) and residual tensile stress (Fig. 6(b)). This leads to the characteristic residual stress profile decreasing with depth. After removal of the cutting tool, the tensile values of the stress are

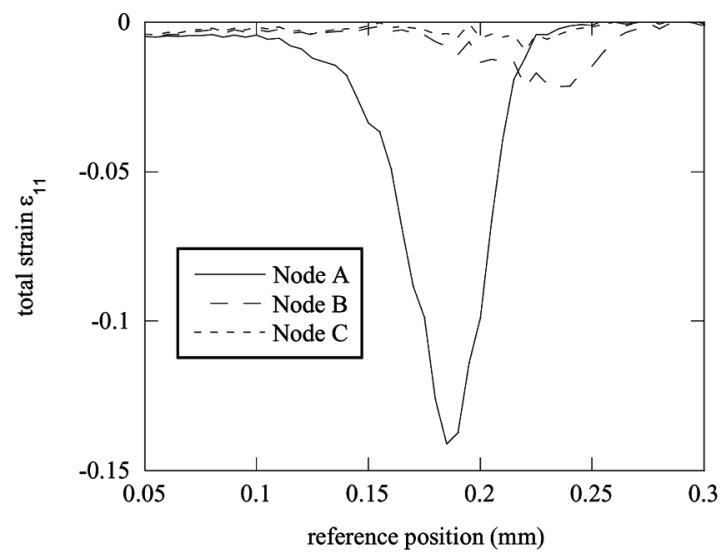

(a)

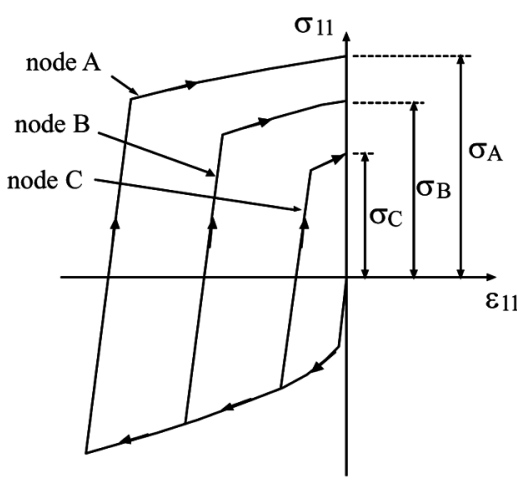

(b)

Figure 6 (a) Time-history of the total strain in direction 1 at the reference points $A, B$ and $C$, obtained by spatial derivation of displacement. (b) Evolution of strain and stress in direction 1 at the reference points $A, B$ and $C$. 
slightly decreased due to the elastic recovery in the workpiece; as a result of this the points at a greater depth may change the sign of the stresses to compression so that the force resultant acting on the cross-section became null (Fig. 7). This qualitative analysis shows the mechanical genesis of tensile residual stresses due to machining. The final values of stresses are also influenced by the thermal strains when these are considered in the analysis, as was shown in Figure 4.

\section{Influence of Friction}

The influence of friction is analysed for rake angle zero and by considering different values of the friction coefficient $\mu: 0,0.1,0.2,0.3$ and 0.4 . Numerical simulations are performed at the cutting speed $2 \mathrm{~m} / \mathrm{s}$, firstly without thermal expansion (see Fig. 8(a) showing $\sigma_{11}$, the same trend was found for $\sigma_{33}$ ). In these conditions the increase of friction decreases substantially the maximum stress level of the tensile layer, although it has only a slight influence on the compressive stresses.

When thermal expansion is considered in the model (see Fig. 8(b)), tensile stresses are enhanced because of the increase of temperature due to friction. However the net effect of a higher friction coefficient is still to diminish the level of the tensile stresses, although the influence is not so accused. The same tendency was observed with all rake angles considered. In order to explain the influence of friction, stress, temperature and velocity fields were analysed during cutting. It was observed that high tensile stresses are generated during cutting in the vicinity of the machined surface for $\mu=0$ and that the level of tensile stresses is reduced for $\mu=0.4$. After unloading and cooling the stress $\sigma_{11}$ remains positive near the free surface but compressive stresses are generated in-depth so as to ensure equilibrium. Similar behaviour is observed for the stress component $\sigma_{33}$.

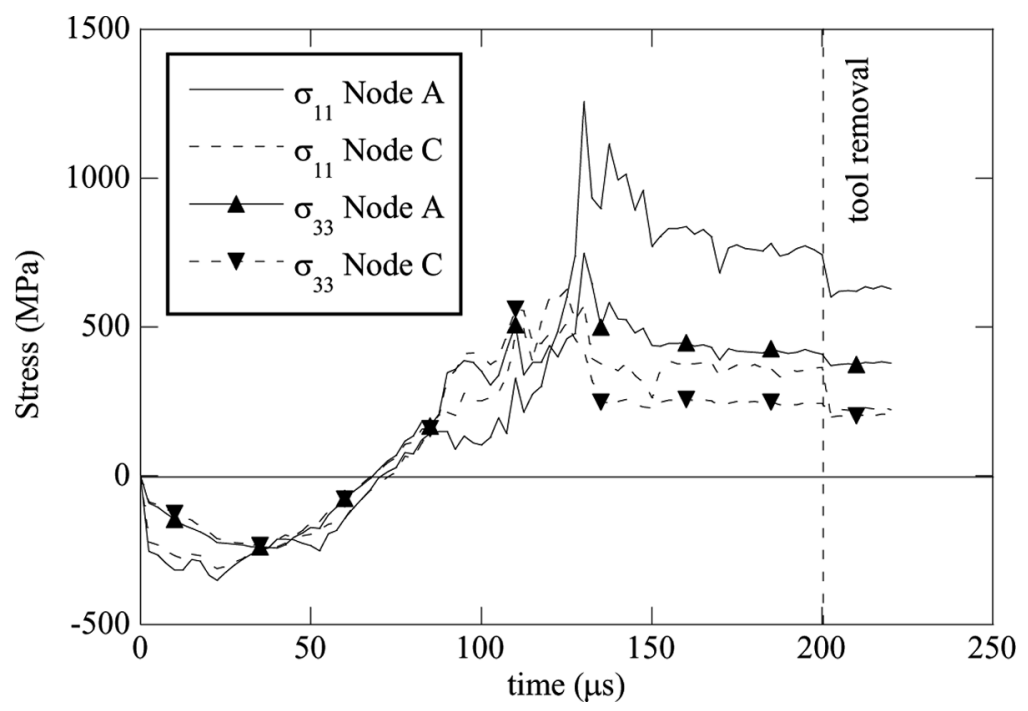

Figure 7 Time-history of the stress in directions 1 and 3 at the reference points $A$ and $C$. 


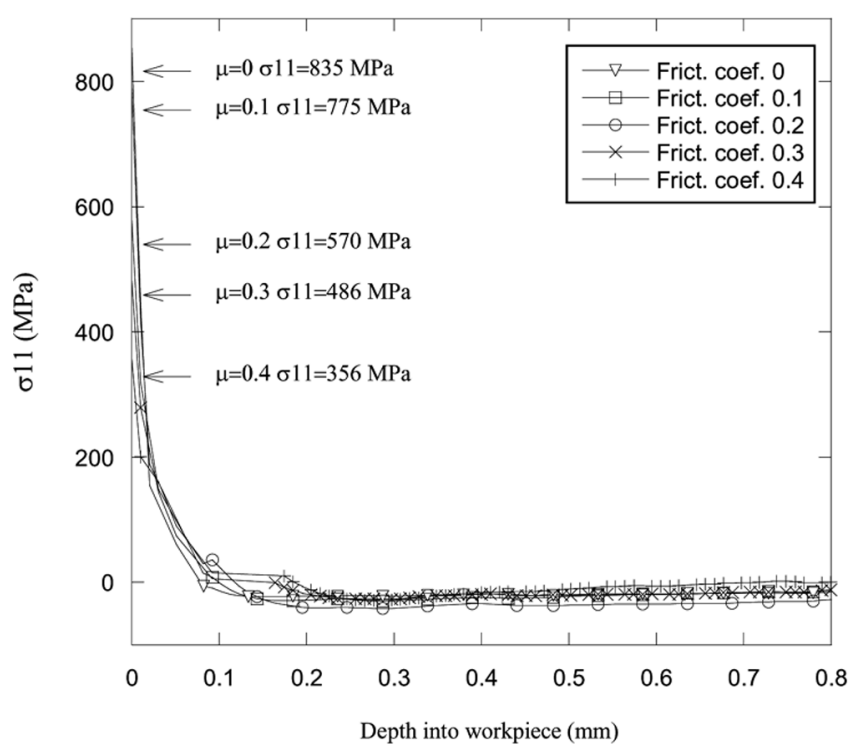

(a)

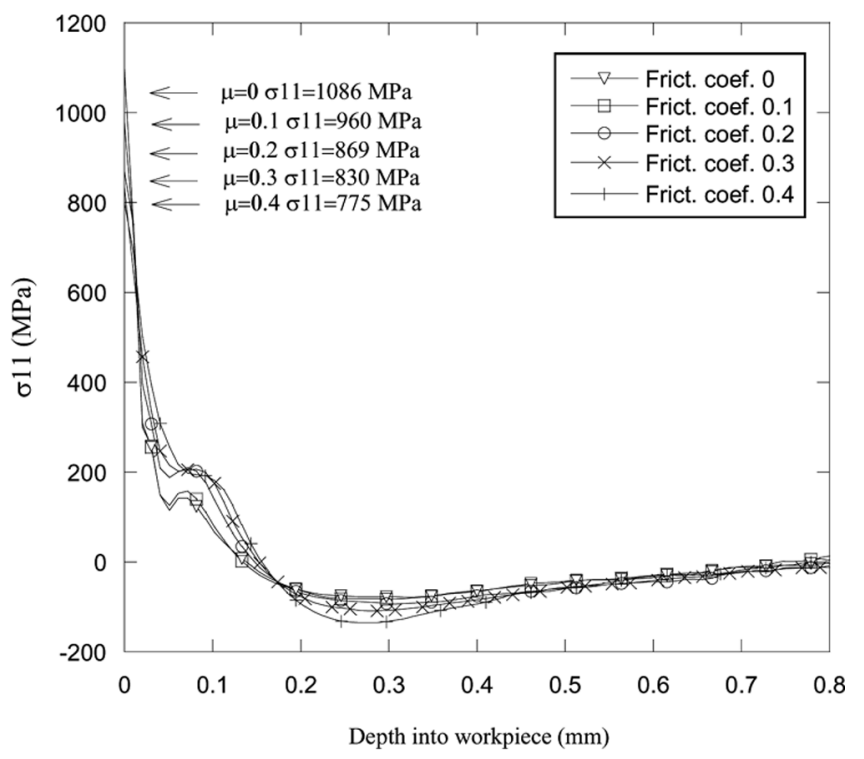

(b)

Figure 8 Influence of the friction coefficient on the residual stresses $\sigma_{11}$. The tool rake angle is zero. For each value of the friction coefficient, the maximum of $\sigma_{11}$ is indicated by an arrow. (a) No thermal expansion and (b) thermal expansion is taken into account.

An increase of temperature of about $200 \mathrm{~K}$ was observed when the friction coefficient was increased from $\mu=0$ to $\mu=0.4$. This increase of temperature induces on the one hand thermal softening, which is shown in the next section to decrease the level of tensile residual stresses. On the other hand, the level of 
tensile stresses is enhanced by the combined effects of higher temperatures and of thermal expansion. Another aspect of the problem is related to the position of the stagnation point during cutting. It is possible to deduce from the observation of the velocity field that increasing the friction coefficient increases the zone where the velocity magnitude is very small, acting like a built up edge. Indeed, when friction is increased, the sticking of the chip with the tool rake face is enhanced and makes the formation of a built up edge easier. The effect of the build-up edge is to provide an effective value of the rake angle which is smaller than the real value. Thus if the rake angle is zero, the effective value of the rake angle would be negative. This effect results in compressive stresses that lower the level of the residual stresses.

To conclude this section, residual stresses are affected by friction in a complex way. Increasing the friction coefficient leads to the competition between different effects, some are increasing the level of tensile stresses (thermal expansion effects are enhanced by frictional heating) while some other are reducing tensile stresses (thermal softening associated to frictional heating, build-up edge effect due to toolchip sticking). The net result of this competition between opposite effects is finally a reduction of the tensile stresses when friction is increased.

\section{Influence of Thermal Softening}

The influence of thermal softening is analysed by changing the total amount of heat generated. The values of the Quinney-Taylor coefficient are imposed artificially as $0.6,0.7$ and 1. No thermal expansion and no friction are taken into account to isolate the effect of thermal softening on residual stresses. The residual stress

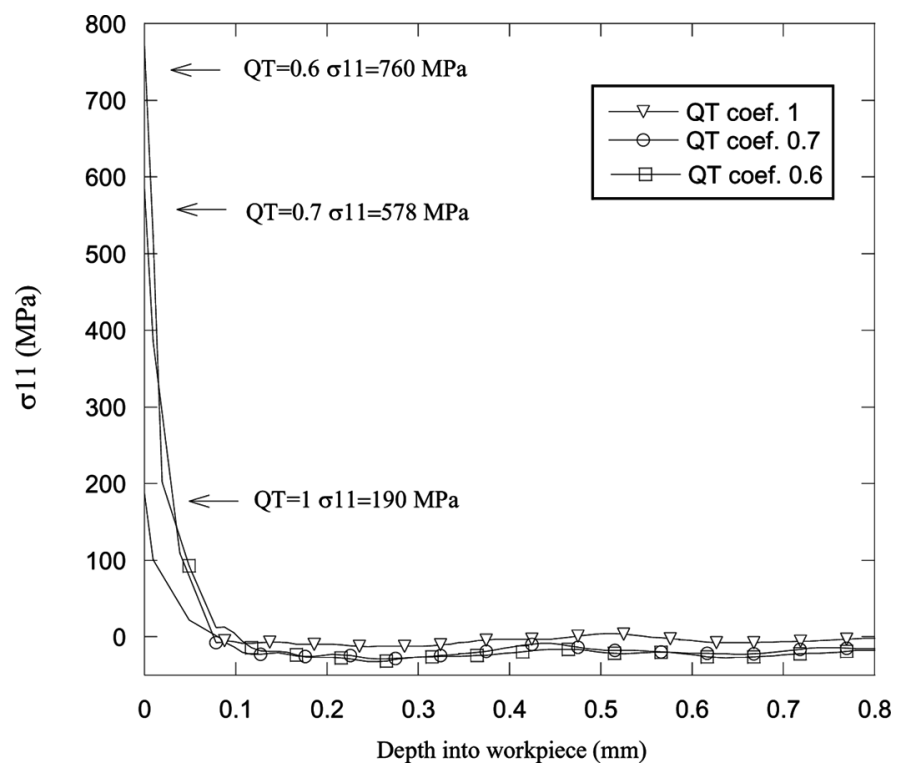

Figure 9 Effect of thermal softening on the residual stresses $\sigma_{11}$ illustrated by varying the value of the Taylor-Quinney coefficient (QT). The rake angle is $-6^{\circ}$. No friction and no thermal expansion are taken into account. For each value of the QT coefficient, the maximum of $\sigma_{11}$ is indicated by an arrow. 


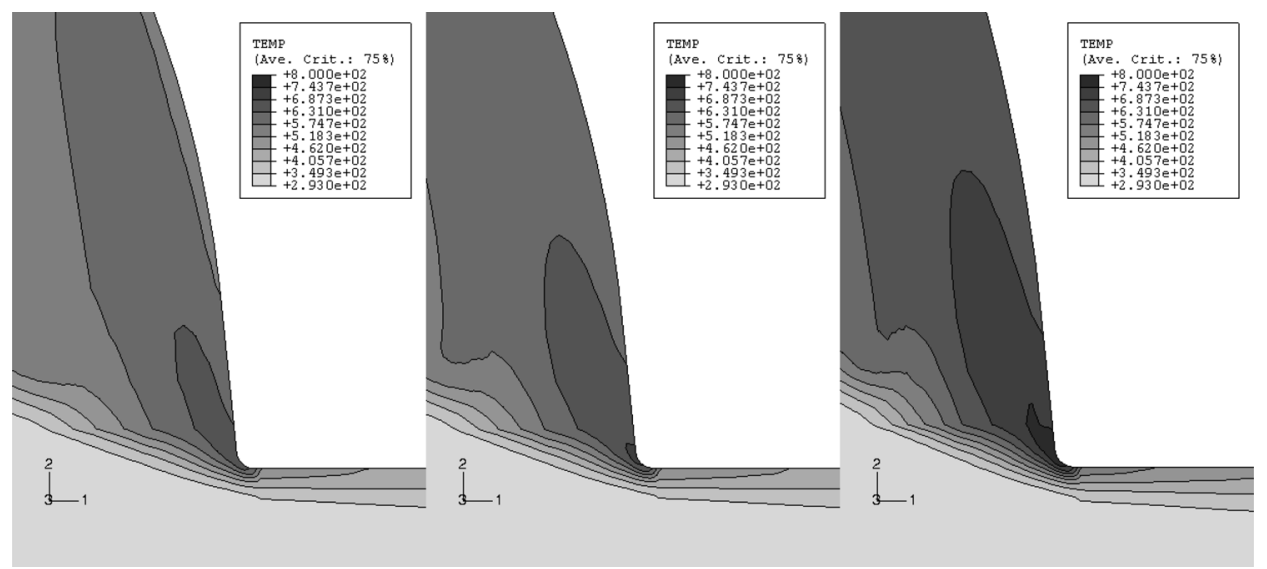

Figure 10 Temperature $(K)$ fields during cutting, from left to right the values of the Taylor-Quinney coefficient are $0.6,0.8$ and 1 . Rake angle $-6^{\circ}$.

distributions for $\sigma_{11}$, Figure 9 corresponding to simulations with negative rake angle $\left(-6^{\circ}\right)$, show that higher Quinney-Taylor coefficients (leading to more heat generation and higher thermal softening) produce a decrease of the level of the tensile stress for $\sigma_{11}$. The same trend was observed in the case of $\sigma_{33}$. Figure 10 shows the difference of temperature fields in each calculation. The effect of a

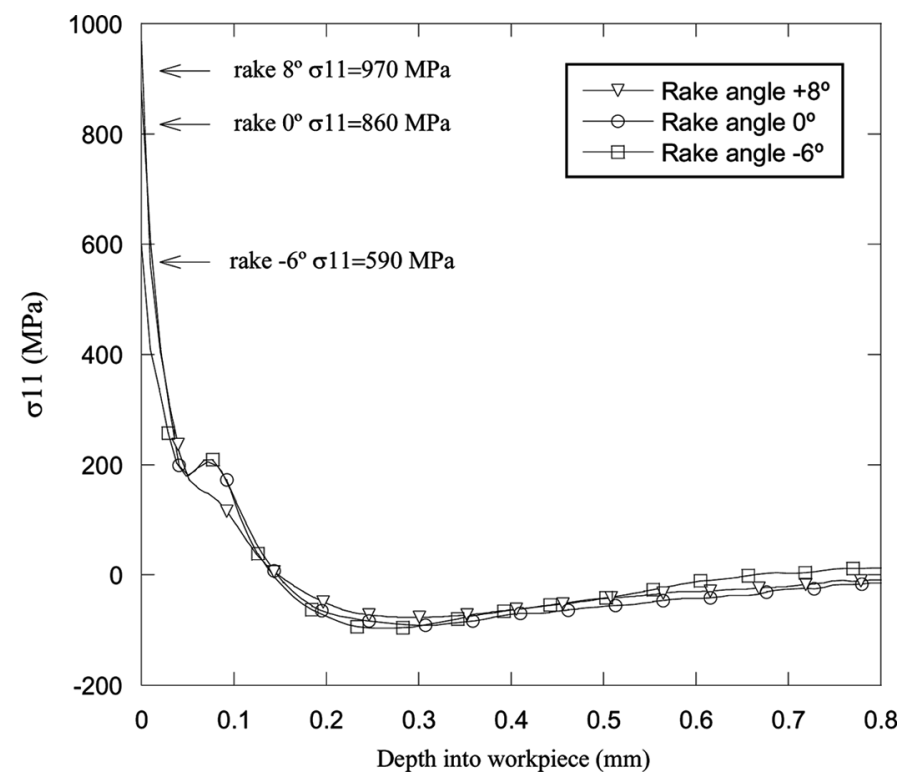

Figure 11 Influence of the tool rake angle on the residual stress $\sigma_{11}$. The values of the rake angle are $-6^{\circ}, 0^{\circ}$ and $+8^{\circ}$. The friction coefficient is 0.2 and thermal expansion is taken into account. For each value of the rake angle, the maximum of $\sigma_{11}$ is indicated by an arrow. 
vanishing Quinney-Taylor coefficient was not studied because of the unrealistic deformation of the chip in absence of thermal softening.

\section{Influence of Tool Rake Angle}

The influence of tool rake angle is analysed by comparing the residual stresses generated with positive $\left(+8^{\circ}\right)$, zero and negative $\left(-6^{\circ}\right)$ rake angles. Simulations were performed with cutting speed equal to $2 \mathrm{~m} / \mathrm{s}$.

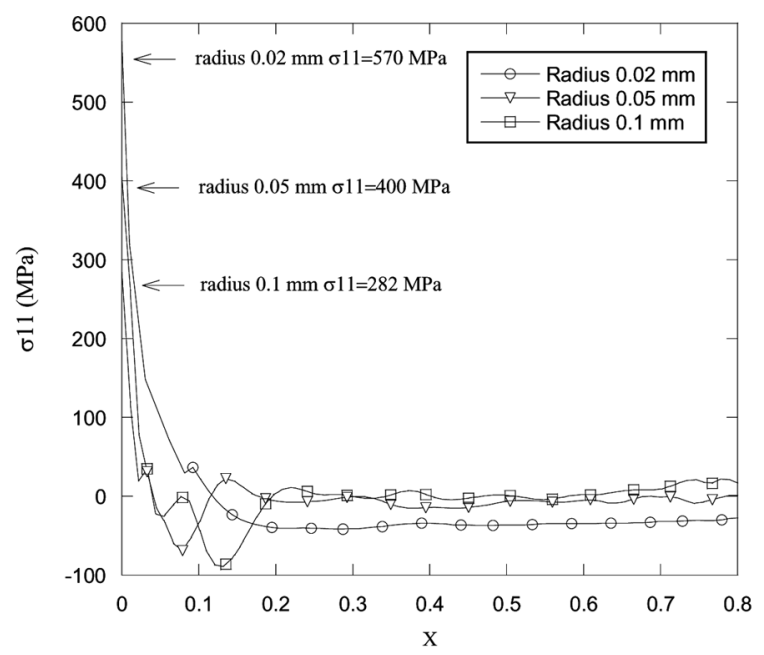

(a)

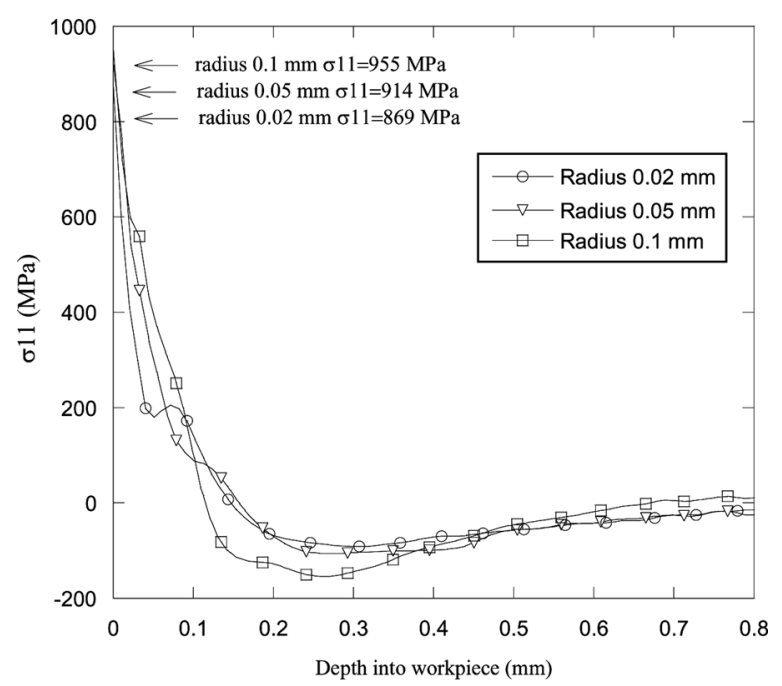

(b)

Figure 12 Influence of the cutting edge radius $(R=0.02,0.05$ and $0.10 \mathrm{~mm})$ on the residual stress $\sigma_{11}$. The friction coefficient is 0.2 . For each value of $R$, the maximum of $\sigma_{11}$ is indicated by an arrow. (a) No thermal expansion and (b) thermal expansion is taken into account. 
Figure 11 shows results obtained with friction coefficient equal to 0.2 and thermal expansion included in the numerical simulation. Tensile level is lowered when the rake angle is decreased. The level of compressive layer is also increased when the rake angle is decreased.

The analysis of stress field $\sigma_{11}$ during cutting, when friction $(\mu=0.2)$ and thermal expansion are considered, showed that the effect of geometry tends to decrease tensile stress as rake angle takes larger negative values, and the effect of friction decreases the maximum value of stress in all geometries. Temperature is increased when the rake angles is decreased. However, when tool rake angle is decreased, the sticking of the chip with the tool rake face increases, resulting in an enhanced built up edge effect (as was previously explained in the analysis of the influence of friction). The net result of this built-up edge is to produce an "effective rake angle," which is smaller than the real rake angle and thus lowers the level of the tensile residual stresses. The competition between these opposite effects is solved with a reduction of the tensile stresses when the rake angle is decreased.

The results obtained for the effect of the rake angle on residual stresses are important for industry. It is commonly observed that positive rake angles generate machined surfaces with higher quality than negative rake angle, and therefore this kind of tools are usually selected for finishing operations. However, when the concept of quality should include those factors influencing service life of the workpiece, like residual stresses, finishing operation with a negative rake angle could be a better choice.

\section{Influence of Tool Edge Radius}

The effect of the tool cutting edge radius on the distribution of residual stresses results again from a complex interplay between thermal and mechanical effects. The analysis is performed for a rake angle equal to zero and by increasing the cutting edge radius from $0.02 \mathrm{~mm}$ in the original model to 0.05 and 0.10 . As before, the mechanical effects are first analysed by neglecting thermal expansion, see Figure 12(a).

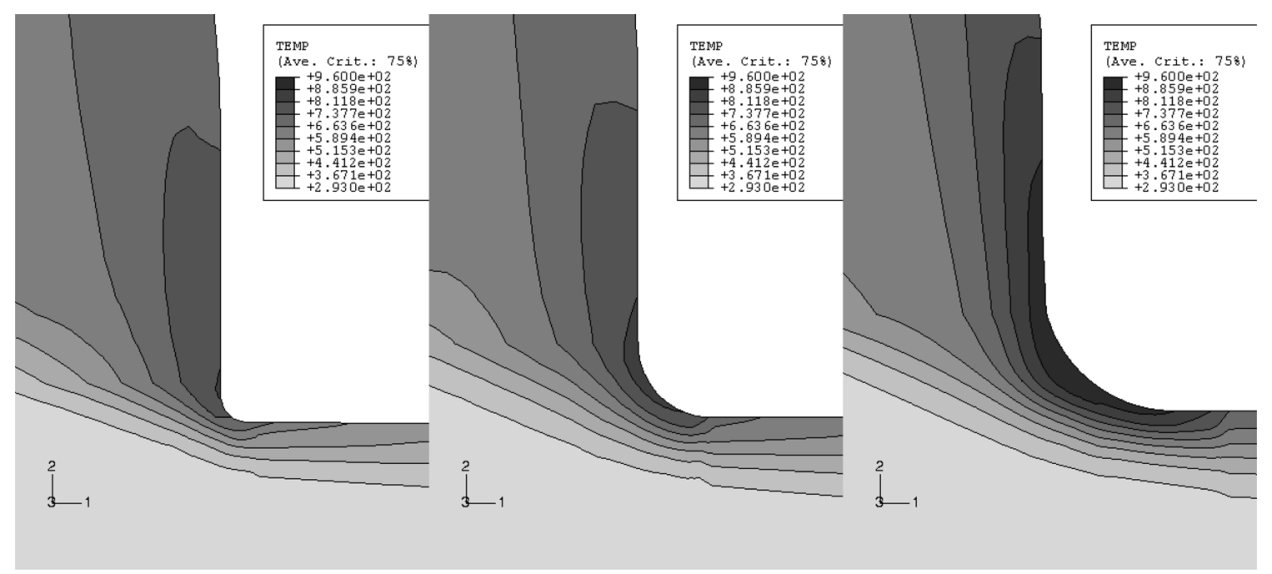

Figure 13 Temperature $(K)$ field during cutting. From left to right the cutting edge radius is $0.05 \mathrm{~mm}$, $0.10 \mathrm{~mm}$ and $0.15 \mathrm{~mm}$. 
Increasing the cutting edge radius seems to have a beneficial effect on tensile residual stresses for the same reason as decreasing the rake angle.

The analysis of velocity field showed the increase of the built-up edge with the cutting edge radius. This built-up edge effect is similar to the one reported for increasing values of the friction coefficient and is beneficial by decreasing the level of tensile stresses. However, when thermal expansion is taken into account the opposite effect is observed (see Fig. 12(b)). Tensile residual stresses are found to become more pronounced for the largest edge radius, and this is attributed to the increase of the workpiece surface temperature (see Fig. 13).

\section{CONCLUSIONS}

This study was focused on the understanding of the mechanisms inducing tensile and compressive residual stresses in the workpiece after machining. In the literature it is widely accepted that tensile stresses are related to thermal expansion effects. It has been shown in this paper that in cutting operations, pure mechanical effects can also contribute to the development of tensile residual stresses. Indeed, it was demonstrated that tensile residual stresses could be generated near the machined surface even in the absence of thermal expansion.

A parametric analysis has been developed where the effects of thermal expansion and of thermal softening were analysed separately (see Table 3 with the summary of the simulations corresponding with figures shown in the paper). It was shown that the level of tensile stresses is higher when: (i) thermal expansion is

Table 3 Overview of the simulations conducted in the paper with the corresponding values of geometrical and material parameters

\begin{tabular}{|c|c|c|c|c|}
\hline \multicolumn{2}{|c|}{ Tool geometry } & \multirow{2}{*}{$\begin{array}{l}\text { Quinney-Taylor } \\
\text { coefficient }\end{array}$} & \multirow{2}{*}{$\begin{array}{l}\text { Thermal } \\
\text { expansion }\end{array}$} & \multirow{2}{*}{$\begin{array}{l}\text { Friction } \\
\text { coefficient }\end{array}$} \\
\hline Rake angle ${ }^{\circ}$ & Cutting edge radius $(\mathrm{mm})$ & & & \\
\hline \multirow[t]{14}{*}{0} & 0.02 & 0.9 & Yes & 0 \\
\hline & & & & 0.1 \\
\hline & & & & 0.2 \\
\hline & & & & 0.3 \\
\hline & & & & 0.4 \\
\hline & & & No & 0 \\
\hline & & & & 0.1 \\
\hline & & & & 0.2 \\
\hline & & & & 0.3 \\
\hline & & & & 0.4 \\
\hline & 0.05 & 0.9 & Yes & 0.2 \\
\hline & & & No & 0.2 \\
\hline & 0.01 & 0.9 & Yes & 0.2 \\
\hline & & & No & 0.2 \\
\hline \multirow[t]{4}{*}{-6} & 0.02 & 0.6 & No & 0 \\
\hline & & 0.7 & No & 0 \\
\hline & & 1 & No & 0 \\
\hline & & 0.9 & Yes & 0.2 \\
\hline 8 & 0.02 & 0.9 & Yes & 0.2 \\
\hline
\end{tabular}


increased and, (ii) thermal softening is decreased. Tensile stresses are also enhanced when (iii) the rake angle is increased, (iv) the friction coefficient is decreased and, (v) the cutting edge radius is increased. How tensile stresses are affected by (i) (ii) (iii) (iv) or (v) is the result of a complex interplay between thermal and mechanical effects, which has been analysed here.

\section{REFERENCES}

1. K. Okushima and Y. Kakino, A Study on the Residual Stress Produced by Metal Cutting, Memoirs of the Faculty of Engineering, Kuyoto, vol. 34, pp. 234-248, 1972.

2. S. Y. Liang and J.-C. Su, Residual Stress Modeling in Orthogonal Machining, Ann. CIRP, vol. 56, no. 1, pp. 65-68, 2007.

3. M. Vaz, Jr., D. R. J. Owen, V. Kalhori, M. Lundblad, and L.-E. Lindgren, Modelling and Simulation of Machining Processes, Arch. Comput. Meth. Eng., vol. 14, pp. 173-204, 2007.

4. K. F. Ehmann, S. G. Kpoor, R. E. DeVor, and I. Lazoglu, Machining Processes Modelling: A Review, J. Manuf. Sci. Eng. Trans. ASME, vol. 119, pp. 655-663, 2006.

5. J. Mackerle, Finite Element Analysis and Simulation of Machining: An Addendum a Bibliography (1996-2002), Int. J. Tools Manuf., vol. 43, pp. 103-114, 2003.

6. D. Y. Jang, T. R. Watkins, K. J. Kozaczek, C. R. Hubbard, and O. B. Cavin, Surface Residual Stresses in Machined Austenitic Stainless Steel, Wear, vol. 194. pp. 168-173, 1996.

7. L. Chen, T. I. El-Wardany, and W. C. Harris, Modelling the Effects of Flank Wear Land and Chip Formation on Residual Stresses, Ann. CIRP, vol. 53, no. 1, pp. 95-98, 2004.

8. M. Nasr, E. G. Ng, and M. A. Elbestawi, Modelling the Effects of Tool-Edge Radius on Residual Stresses when Orthogonal Cutting AISI316L, Inter. J. Mach. Tools Manuf., vol. 47, pp. 401-411, 2007.

9. D. Umbrello, R. M'Saoubi, and J. C. Outeiro, The Influence of Johnson-Cook Material Constants on Finite Element Simulation of Machining of AISI 316L Steel, Int. J. Mach. Tools Manuf., vol. 47, pp. 462-470, 2007.

10. C. R. Liu and Y. B. Guo, Finite Element Analysis of the Effect of Sequential Cuts and Tool/Chip Friction on Residual Stresses in a Machined Layer, Int. J. Mech. Sci., vol. 42, pp. 1069-1086, 2000.

11. M. Salio, T. Berruti, and G. De Poli, Prediction of Residual Stress Distribution Alter Turning in Turbine Disks, Inter. J. Mech. Sci., vol. 48, pp. 976-984, 2006.

12. J. C. Outeiro, A. M. Dias, J. L. Lebrun, and V. P. Astakhov, Machining Residual Stresses in AISI316L Steel and Their Correlation with the Cutting Parameters, Mach. Sci. Technol., vol. 6, no. 2, pp. 251-270, 2002.

13. J. C. Outeiro and A. M. Dias, Influence of Work Material Properties on Residual Stresses and Work Hardening Induced by Machining, Mater. Sci. Forum, vol. 524-525, pp. 575-580, 2006.

14. R. M'Saoubi, J. C. Outeiro, B. Changeux, J. L. Lebrun, and A. Moräo Dias, Residual Stress Analysis in Orthogonal Machining of Standard and Resulfurized AISI 316L Steels, J. Mater. Proc. Tech., vol. 96, pp. 225-233, 1999.

15. J. C. Outeiro, A. M. Dias, and I. S. Jawahir, On the Effects of Residual Stresses Induced by Coated and Uncoated Cutting Tools with Finite Edge Radii in Turning Operations, Ann. CIRP, vol. 55, no. 1, pp.111-116, 2006.

16. J. C. Outeiro, D. Umbrello, and R. M'Saoubi, Experimental and FEM Análisis of Cutting Sequence on Residual Stresses in Machined Layers of AISI 316L Steel, Mater. Sci. Forum, vol. 524-525, pp. 179-184, 2006. 
17. Z.-C. Lin, Y.-Y. Lin, and C. R. Liu, Effect of Thermal Load and Mechanical Load on the Residual Stress of a Machined Workpiece, Int. J. Mech. Sci., vol. 33, no. 4, pp. 263-278, 1991.

18. M. Bäker, Finite Element Simulation of Chip Formation, Shaker Verlag, Aachen, 2004.

19. M. Barge, H. Hamdi, J. Rech, and J. M. Bergheau, Numerical Modelling of Orthogonal Cutting: Influence of Numerical Parameters, J. Mat. Pro. Tech., vol. 164165, pp. 1148-1153, 2005.

20. T. H. C. Childs and K. Maekawa, Computer-aided Simulation and Experimental Studies of Chip Flow and Tool Wear in the Turning of Low Alloy Steels by Cemented Carbide Tools, Wear, vol. 139, pp. 235-250, 1990.

21. M. H. Dirikolu, T. H. C. Childs, and K. Maekawa, Finite Element Simulation of Chip Flow in Metal Machining, Inter. J. Mech. Sci., vol. 43, pp. 2699-2713, 2001.

22. T. D. Marusich and M. Ortiz, Modelling and Simulation of High-Speed Machining, Inter. J. Numer. Meth. Eng., vol. 38, pp. 3675-3694, 1995.

23. E. Ceretti, P. Fallböhmer, W. T. Wu, and T. Altan, Application of 2D FEM to Chip Formation in Orthogonal Cutting, J. Mater. Proc. Technol., vol. 59, pp. 169-181, 1996.

24. E. Ceretti, M. Lucchi, and T. Altan, FEM Simulation Orthogonal Cutting: Serrated Chip Formation, J. Mater. Proc. Tech., vol. 95, pp. 17-26, 1999.

25. T. Özel and T. Altan, Process Simulation Using Finite Element Method Prediction of Cutting Forces, Tool Stresses and Temperatures in High Speed Flat end Milling Process, Inter. J. Mach. Tools Manuf., vol. 40, no. 5, pp. 713-738, 2000.

26. T. Özel and T. Altan, Determination of Workpiece Flow Stress and Friction at the Chip-Tool Contact for High-Speed Cutting, Inter. J. Mach. Tools Manuf., vol. 40, no. 1, pp. 133-152, 2000.

27. M. Bäker, J. Rosler, and C. Siemers, A Finite Element Model of High Speed Metal Cutting with Adiabatic Shearing, Comput. Struct., vol. 80, pp. 495-513, 2002.

28. K. S. Woon, M. Rahman, F. Z. Fang, K. S. Neo, and K. Liu, Investigations of Tool Edge Radius Effect in Micromachining: A FEM Simulation Approach, J. Mater. Proc. Technol., vol. 195, no. 1, pp. 204-211, 2008.

29. M. R. Movahhedy, Y. Altintas, and M. S. Gadala, Numerical Analysis of Metal Cutting with Chamfered and Blunt Tools, Trans. ASME, J. Manuf. Sci. Eng., vol. 124, pp. 178-188, 2002.

30. L. Olovsson, L. Nilsson, and K. Simonsson, An A.L.E. Formulation for the Solution of Two-Dimensional Metal Cutting Problems, Computers and Structures, vol. 72, pp. 497-507, 1999.

31. E. Ceretti, L. Filice, D. Umbrello, and F. Micari, ALE Simulation of Orthogonal Cutting: A New Approach to Model Heat Transfer Phenomena at the Tool-Chip Interface, Ann. CIRP, vol. 56, no. 1, 2007.

32. M. Movahhedy, M. S. Gadala, and Y. Altintas, Simulation of the Orthogonal Metal Cutting Process Using an Arbitrary Lagrangian-Eulerian Finite-Element Method, J. Mater. Proc. Technol., vol. 103, pp. 267-275, 2000.

33. O. Pantalé, J.-L. Bacaria, O. Dalverny, R. Rakotomalala, and S. Caperaa, 2D and 3D Numerical Models of Metal Cutting with Damage Effects, Comp. Meth. Appl. Mech. Eng., vol. 193, pp. 4383-4399, 2004.

34. Hibbit Karlson and Sorensen Inc., ABAQUS/Explicit User's Manual, 6.4-1, 2003.

35. T. Özel and E. Zeren, Finite Element Modelling of Stresses Induced by High Speed Machining with Round Edge Cutting Tools, Proc. IMECE'05, Orlando, Florida, November 5-11, 2005.

36. H. Miguélez, R. Zaera, A. Rusinek, A. Moufki, and A. Molinari, Numerical Modelling of Orthogonal Cutting: Influence of Cutting Conditions and Separation Criterion, J. Phys. IV, vol. 134, pp. 417-422, 2006. 
37. G. Barrow, A Review of Experimental and Theoretical Techniques for Assessing Cutting Temperatures, Ann. CIRP, vol. 22, no. 2, pp. 203-211, 1973.

38. A. O. Schmidt, O. W. Gilbert, and A. Boston, Thermal Balance Method and Mechanical Investigation for Evaluating Machinability, Trans. ASME, vol. 67, 1945.

39. A. Moufki, A. Molinari, and D. Dudzinski, Modelling of Orthogonal Cutting with a Temperature Dependent Friction Law, J. Mech. Phys. Solids, vol. 46, no. 10, pp. 2103-2138, 1998.

40. T. H. Childs, K. Maekawa, T. Obikawa, and Y. Yamane, Metal Machining-Theory and Applications. Arnold, London, 2000.

41. K. Komvopoulos and S. A. Erpenbeck, Finite Element Modeling of Orthogonal Metal Cutting, ASME J. Eng. Indus., vol. 113, pp. 253-267, 1991.

42. A. J. Shih, S. Chandrasekar, and H. T. Yang, Finite Element Simulation of Metal Cutting Process with Strain-Rate and Temperatures Effects, Fund. Issues Mach. ASME, PED, vol. 43, pp. 11-24, 1990.

43. Z. C. Lin and S. Y. Lin, A Couple Finite Element Model of Thermo-Elastoplastic Large Deformation for Orthogonal Cutting, ASME J. Eng. Indus., vol. 114, pp. 218-226, 1992.

44. J. Shi and C. R. Liu, The Influence on Material Models on Finite Element Simulation of Machining, J. Manuf. Sci. Eng., vol. 126, pp. 849-857, 2004.

45. G. R. Johnson and W. H. Cook, A Constitutive Model and Data for Metals Subjected to Large Strains, High Strain Rate and Temperature, Proc. Inter. Symp. Ballist., pp. 541-547, 1983.

46. M. Barge, H. Hamdi, J. Rech, and J.-M. Bergheau, Numerical Modelling of Orthogonal Cutting: Influence of Numerical Parameters, J. Mater. Proc. Technol., vol. 164-165, pp. 1148-1153, 2005.

47. T. Mabrouki, J.-F. Rigal, A Contribution to a Qualitative Understanding of Thermomechanical Effects During Chip Formation in Hard Turning, J. Mat. Process. Tech., vol. 176, pp. 214-221, 2006.

48. H. Chandrasekaran, R. M'Saoubi, and H. Chazal, Modelling of Material Flow Stress in Chip Formation Process from Orthogonal Milling and Split Hopkinson Bar Tests, Mater. Sci. Technol., vol. 9, pp. 131-145, 2005.

49. M. N. A. Nasr, E.-G. Ng, and M. A. Elbestawi, Effects of Strain Hardening and Initial Yield Strength on Machining-Induced Residual Stresses, J. Eng. Mater. Technol., vol. 129 , pp. 567-579, 2007.

50. N. Tounsi, J. Vincenti, A. Otho, and M. A. Elbestawi, From the Basics of Orthogonal Metal Cutting Toward the Identification of the Constitutive Equation, Inter. J. Mach. Tools Manuf., vol. 42, no. 2, pp. 1373-1383, 2002. 